\title{
Vocabulary Acquisition Style in the ESL Classroom: A Survey on the Use of Vocabulary Learning Strategies by the Primary 3 Learners
}

\author{
Aliceson Linda, Parilah Mohd Shah \\ Faculty of Education, Universiti Kebangsaan Malaysia, Bangi, Malaysia \\ Email: bella.aldama82@gmail.com,drparila@gmail.com
}

How to cite this paper: Linda, A., \& Shah, P. M. (2020). Vocabulary Acquisition Style in the ESL Classroom: A Survey on the Use of Vocabulary Learning Strategies by the Primary 3 Learners. Creative Education, 11, 1973-1987.

https://doi.org/10.4236/ce.2020.1110144

Received: September 4, 2020

Accepted: October 19, 2020

Published: October 22, 2020

Copyright $\odot 2020$ by author(s) and Scientific Research Publishing Inc. This work is licensed under the Creative Commons Attribution International License (CC BY 4.0).

http://creativecommons.org/licenses/by/4.0/

\begin{abstract}
The factor that influences the effectiveness of vocabulary acquisition is the use of vocabulary learning strategies. It is one of the crucial factors that affect the success of English vocabulary learning. This study aims to explore the vocabulary learning strategies that mostly preferred by Primary 3 school pupils in a primary school of Padawan district, Sarawak. The survey design was employed and used questionnaire to collect the data from the participants. They were randomly chosen from Primary 3 class. Seven vocabulary learning strategies were adapted in conducting the survey namely dictionary strategies, guessing strategies, study preferences, memory strategies, autonomy learning, note-taking strategies and social strategies. The outcomes showed that majority of primary 3 pupils were strongly agreed that memory strategies were the most preferred strategies used to learn vocabulary, followed by dictionary strategies and guessing strategies. Thus, language teachers are recommended to be aware of the pupils' learning styles at different proficiency, and apply various teaching and learning methods according to current education contexts.
\end{abstract}

\section{Keywords}

English Vocabulary, Vocabulary Learning Strategies, Primary School, Survey

\section{Introduction}

The vocabulary acquisition knowledge is the most challenging aspect for learners specifically for the Malaysian pupils from elementary level. It is multi-faceted and is taught indirectly. Hence, most low proficiency learners are facing the hurdles of learning the Second Language. To function well in the second lan- 
guage (L2), they have to get familiar with some learning strategies that may enhance their Second language vocabulary acquisition. Nation (2001) claims that Vocabulary learning strategies are "part of general learning strategies". The vocabulary learning strategies are the learning methods that learners apply for active and self-directed language learning. O'Malley \& Chamot (1990) claimed that learners' language achievement and proficiency are strongly associated with the conscious, orchestrated and tailored uses of the vocabulary language learning strategies. Thus, this pilot study intends to discover the frequently used of vocabulary learning strategies among the Primary 3 pupils and to test the adequacy of the survey instrument.

\subsection{Vocabulary Learning Strategies}

The characteristic of vocabulary learning skills is different from any other language learning skills that "vocabulary learning is incremental, potentially limitless, and heavily constrained by the learners' experience" (Waldvogel, 2013). In the present years, vocabulary learning strategies has been gaining more attention among language researchers to help in explaining the difficulties of most language learners encountered when learning vocabulary. It has also has attracted the researchers' interest who have the attempt to investigate and classify vocabulary learning strategies. According to O'Malley \& Chamot (1990), vocabulary learning strategies are "special thoughts or behaviours that individuals use to comprehend, learn or retain information." Meanwhile, Oxford (1990) defined them as "specific actions or behaviours accomplished by learners to enhance learning". In contrast, $\mathrm{Gu}$ (2005) refers the vocabulary learning strategies as "what learners utilize when confronting with a learning task". Hence, vocabulary learning strategies are the methods that utilized by the learners to enhance their learning skills in more effective way.

\subsection{Background of the Study}

Since the aligned CEFR English Language new curriculum was introduced, the vocabulary learned also become wider specifically for the Primary 3 pupils. The lists of vocabulary are compiled from the Cambridge English Learner Corpus. The Year 3 Core Vocabulary also being introduced which means pupils learn the vocabulary by category. The main categories are adjectives, verbs, fixed phrases, health, sports and also in alphabetical order. The vocabulary learning from the Cambridge English Learners Corpus not only applicable for Primary 3 pupils but it also will be expanded in the Primary 4 and Primary 5 English CEFR aligned curriculum with more new vocabulary to be used. Most pupils in the sub-urban school would not be able to grasp the newly learned words due to their low proficiency level. Some vocabulary may unfamiliar to these pupils because they are not the English native speakers and communicate in their mother tongue or Malay Language frequently. Besides, they are from different socioeconomic background and may not apply the English language in their interaction all the time. 
The main factor need to be considered in being a good English speaker is to acquire as much as possible the new English vocabulary. The pupils may need certain learning strategies to cater this need as to improve their English language and to be more competent in using the second language. Ghazal (2007) suggested that using the learning strategy and instruction is an essential part of learning any foreign language or second language. In view of this matter, this pilot study is to explore the types of vocabulary learning strategies used by the Primary 3 pupils to acquire the English Vocabulary.

\subsection{Problem Statement}

Vocabulary learning is still not being given enough emphasis in the Malaysian ESL classroom contexts as English is less spoken during daily communication and is taught only for the purpose of passing examinations. Nowadays, English vocabulary is pivotal for smooth communication so that ideas can be expressed well specifically in the international businesses and job markets. In each level of English vocabulary competence, there is glossary provided according to British English Version and the American English Version. The glossary may comprise of words, phrases, verbs and idioms. These word categories signify the actual language competence of learners based on the CEFR competency level (A1 to C2). As for the Primary 3 pupils, the words and phrases may difficult for them to differentiate since the meanings come in different frequency. Pupils with limited language competency may unable to comprehend the reading materials and their learning process may distracted.

To date, there are more advanced and expanding learning materials and multimedia based technology that could assist our young learners in acquiring a wide range of English vocabulary. Most sub-urban primary pupils never bother to master the English vocabulary as learning the second language is not their prior interest, unless it started within their social encounters and family upbringing. When they are in the ESL classroom, the learning usually focused on learning the language items for passing the examination and less exposure on vocabulary. Basically, the vocabulary learning only occurs when they doing the reading activities and comprehending texts (Pritchard, 1990). In fact, this happened in the present school and pupils usually jot down the new vocabulary and write their meaning without any practical use of the words after the learning session. For most sub-urban children whose English language is not their first language, reading is a "suffocating slow process" (Noor \& Amir, 2009). The pupils also not comprehend well the entire text since they are insufficient of vocabulary knowledge and reading activities require accurate words recognition skill. Pupils who have limited proficiency in the second language also have difficulties in expressing ideas, conveying messages and speech spontaneously. Instead of these, frequent pauses would impede their communication with the audiences. Therefore, with regards to the matters mentioned, this study is intended to explore the different vocabulary learning strategies used by the Primary 3 pupils. 


\subsection{Research Questions}

Based on the mentioned issues, this pilot study aims to explore which vocabulary learning strategies are employed by the Primary 3 pupils and to further discover the adequacy of this survey instrument used. The significant relationship between their language competency and the amount of strategies used also will be identified and thus, the study tends to answer the questions as follow:

1) What are the pupils' vocabulary learning strategies preferences?

2) Is there a significant relationship between student's language competency and the number of vocabulary learning strategies used?

\section{Literature Review}

In the previous chapter, the background of the study has been dis-cussed and followed by the problem statement and the research questions that to be addressed. Learners are encouraged to utilize multiple learning strategies when learning and acquire second language (Gu \& Johnson, 1996; O’Malley \& Chamot, 1990; Schmitt \& McCarthy, 1997). A study by Rafik-Galea and Wong (2006) on adult university foreign language learners revealed that cognitive strategies were highly preferred than other strategies, and metacognitive are the least employed. This means that the respondents often took practice on the vocabulary they learned and able to manipulate and transform the target language to suits their understanding.

Likewise, Gu \& Johnson (1996) has revealed in their study on the first-year university students who were non-English speakers that they preferred metacognitive strategies the most, specifically on the self-initiation and selective attention. Metacognitive strategies involves planning, monitoring, and evaluating learning experiences that learners need to develop additional efforts when acquire vocabulary (O'Malley \& Chamot, 1990). Besides that, the respondents also use the guessing strategies extensively from the compensation strategies to learn English words. When reading a text, they made use of the surrounding contexts to search for clues. As such, both studies has unveiled that learners tend to use multiple strategies to learn Second language vocabulary. Schmitt \& McCarthy (1997) conducted a study on some Japanese learners on the usage pattern of various vocabulary learning strategies and found out the use of bilingual dictionary was the most favorable and followed by guessing the meaning in context. Both strategies are from determination strategy and the second frequently used strategy is asking their peers. This involves the social strategies and determination with social strategies is derived from discovery strategies. Under Schmitt's taxonomy of learning strategies, these vocabulary learning strategies are categorized in discovery and consolidation strategies. The other most used strategies are the massive form to study spelling, say a new vocabulary aloud and study the sound of the word. The study also showed that in the consolidation strategies, learners also use verbal and written repetitions to learn the vocabulary. Thus, this pilot study aims to determine if the use of different and various vocabulary 
learning strategies would be sufficient to cater the pupils' vocabulary acquisition.

\subsection{Vocabulary as the Crucial Elements in Language Learning}

To date, the lexical knowledge of language learning has gained further development and interests among scholars towards vocabulary size and the amount of words. This is also applied to the primary school pupils that certain vocabulary groups need to be acquired according to the lexical base of some basic word families. Both receptive and productive skills in the language need vocabulary as a pre-requisite in the communication process. The receptive skill is common through reading materials and listing words whereby the meaning of words are carried out through communication. Therefore, learners need to master an adequate number of words to comprehend the reading and listing items. Nation (2001) suggested that in order to obtain more reasonable comprehension in reading materials and to be good in guessing meaning from the contexts, learners need to know at least $95 \%$ of the running vocabulary in the input from each language skill. Thus, the use of vocabulary learning strategies is the crucial part to ensure the pupils mastered the sufficient vocabulary based on their proficiency level. Similarly, the productive skills (speaking and writing) also need sufficient amount of vocabulary to convey messages and express the meanings. Likewise, without adequate vocabulary size, learners may fail to express their messages and ideas to their respective audiences.

\subsection{Conceptual Framework}

Based on this study, a conceptual framework is constructed to de-scribe briefly the use of various vocabulary learning strategies and its relationship that may exists between learners' language competency and the number of vocabulary learning strategies use (Figure 1).

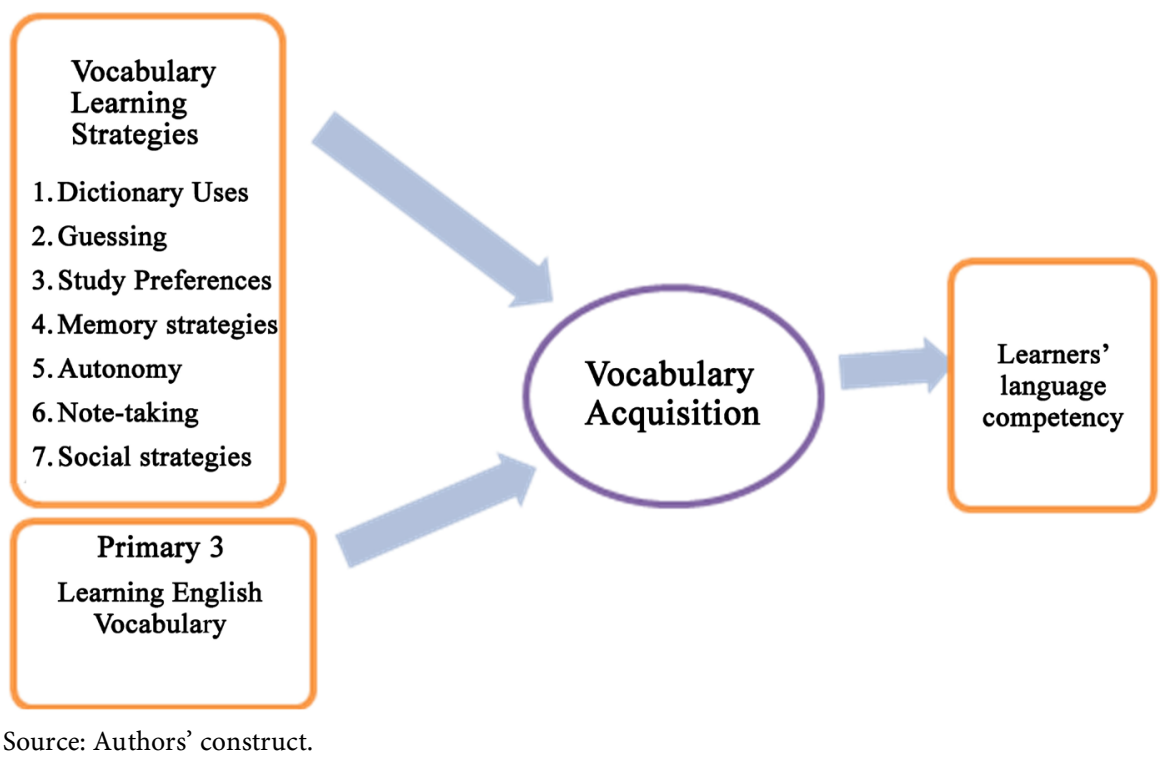

Figure 1. Conceptual framework on primary learners' vocabulary acquisition. 
From the framework above, it is indicated that vocabulary acquisition derives from various types of vocabulary learning strategies that they would use in frequent. The latter will resulted in learners' language competency based on the number of strategies they adopt.

\subsection{Theoretical Perspectives}

\subsubsection{Vocabulary Definition}

Vocabulary is defined as knowledge of words, and includes the understanding of word meanings. In brief, vocabulary is a word sound or a combination of sounds and it represents the writing or printing inputs that signify and produce a meaning. Generally, the word meanings can be retrieved from the dictionary. However, a word can be more confusing when it has a different meaning in different contexts. This factor involves the word register and happens in daily life situation. For instant, the word "gold" has a basic meaning in a dictionary which means "a chemical element that is valuable, shiny, yellow metal used to make coins and jewellery". Conversely, during an informal situation, it is used to refer to something special or valuable. In the association aspect, words are related in different ways and may belong to certain word groups. According to Aitchison (2003), there are four main categories of word association. First, the coordination, such as the words cluster on the same detail and level, for example, apple and orange. In contrast, the opposite words also engaged with this type of cluster such as in full and hungry. Next is the super-ordination which is the general part of the words can subordinate to the specific words. When we mention the word flower, the other can associate it with roses and sunflower. The third element is the synonym, meanings that the word is having the same meaning and grouped together in the vocabulary profile. For example like sad and gloomy. The last one is the collocation which is some words are meant to be collocate together. For instant, salt water.

\subsubsection{The Taxonomy of Vocabulary}

Vocabulary learning strategies has close connection with language learning strategies. Learning strategies is the approach that learners utilized to achieve their learning tasks. Basically, there are five steps: “1) Facing with the word, 2) Getting an image of the word in mind, 3) Learning the meaning, 4) Making a strong connection between form and meaning, 5) Using the word" (Fan, 2003). With regards to this concept, they are mainly used in learning vocabulary and grammar, literature, and other language components. Many linguists and language researchers have developed some useful taxonomy of language learning strategies. To understand about the taxonomy in detail, the most common are Oxford (1990), Gu \& Johnson (1996), Schmitt \& McCarthy (1997), and Nation (2001).

Oxford has developed the Strategy Inventor of Language Learning (SILL) that consists of direct and indirect strategies. Direct strategies have three sub-strategies which are memory strategies, cognitive strategies, and compensation strategies, whereas indirect strategies are divided into meta-cognitive strategies, affective 
strategies and social strategies. The Oxford Taxonomy also emphasis on that while learners learn vocabulary, they will become autonomous and responsible for their own learning. Benson (2001) also suggested that the independence level of EFL/ESL learners will increase when they explicitly being taught about the learning strategies.

Next, Schmitt's vocabulary learning strategies are classified into the discovery strategies to discover new word's meaning and consolidating strategies is for consolidating a word once the words have been encountered. (Schmitt \& McCarthy, 1997; Schmitt, 2000) adapted the strategies from Oxford's (1990) vocabulary learning strategies that are function in approximately 58 vocabulary learning strategies that he developed. The discovery of a new word's meaning also comprised of determination and social strategies. Similarly, Schmitt and Schmitt (1995) have emphasized the importance of vocabulary learning strategies knowledge that the strategies should be included in the educational programs and school syllabuses. In contrast, O'Malley \& Chamot (1990) have only a classification of learning strategies which are quite similar to Oxford's: Metacognitive, cognitive and social/ affective strategies.

Furthermore, Nation (2001) has developed three general classes of strategies which are "planning", "source" and "processes". In "planning", learners have to decide on where, how and to what extend that they should focus on their vocabulary items that they learn. "Sources" refers to items used in learning for instance like dictionaries, textbooks or other resources to help them acquire the second language vocabulary, and "Processes" include the establishing of words knowledge through noticing and generating strategies. He also suggested that vocabulary learning has the burden of learning which acts as the amount of effort that learners need to gain when obtain new lexical items. He added on "different words have different learning burdens for learners with different backgrounds and each of the aspects of what it means to know a word can contribute to its learning burden".(p. 23). Thus, the educators and teachers should be aware of various types of vocabulary learning strategies in order to guide the learners to learn second language better.

In this study, the taxonomy of $\mathrm{Gu}$ and Johnson was adopted. Their second language vocabulary strategies are meta-cognitive regulation, Cognitive strategies such as guessing strategies, dictionary strategies, memory strategies (rehearsal and encoding) and the activation strategies. The rehearsal strategies involve acquiring the wordlists and repeat the new words learned. Gu and Johnson (as cited in Goundar, 2019) emphasised that "learners using guessing strategies draw upon their background knowledge and use linguistic clues like grammatical structures of a sentence to guess the meaning of a word". Meanwhile, the encoding strategies comprised the association of words, imagery, visual, auditory, semantic, and contextual encoding along with word structure which includes; analyse the words in terms of prefixes, stems, and suffixes' (Gu \& Johnson, 1996). 


\section{Methodology}

A survey design and quantitative approach are employed and using questionnaires to obtain the frequencies and the correlation between the vocabulary learning strategies used and their language competency. The rationale of employing the survey design is to obtain some inferences about the pupils' learning preferences in vocabulary learning. The vocabulary strategies questionnaire was adapted from a study by Hadavi \& Hashemi (2014). It is also written in bilingual (Malay and English language) to ease the understanding of some pupils who do not perform well in English Language. The respondents consisted of 20 pupils (n $=20$ ) and they were 10 males and 10 females by random sampling. The instrument consisted of 14 items; 12 items were answered in the form of Likert Scales ranged from 1 to 4,1 item of ticking the box to select only 1 answer about their study preference (s), and 1 item of open-ended question which asked about their Vocabulary learning preference(s) and provide reasons of selecting the strategies. The respondents answered the items using a 4-point Likert Scales, ranged from strongly agree (1), agree (2), disagree (3), and strongly disagree (4). The survey items need to be clarified whether it is reliable and valid. Thus, a reliability test was conducted to determine the validity and reliability of the instruments used.

Table 1 indicates that the survey questionnaire has the consistency with the Cronbach's Alpha is 0.782 . This indicates that the measurement items of the questionnaire are reliable and consistent, thus can be employed in the study to obtain the responses regarding the use of vocabulary learning strategies. This study was conducted during the Malaysian Movement Control Order due to the COVID-19 pandemic. Thus, the questionnaire was constructed and distributed through Google Form as the survey was not able to be conducted directly and social distancing was ordered. The question items were developed by $\mathrm{Gu} \&$ Johnson (1996) and adopted by previous researchers (Fan, 2003; Gu \& Johnson, 1996; Nation, 2001; O’Malley \& Chamot, 1990; Oxford, 1990; Schmitt, 2000) and were being modified to suit the respondents' comprehension.

\section{Findings}

\subsection{What are the Pupils' Vocabulary Learning Strategies Preferences?}

From this study, it was revealed that the 20 respondents $(n=20)$ were using different types of vocabulary learning strategies to acquire the English vocabulary. To answer the first research question of this study, the data is recorded by using the descriptive statistic to find the frequencies of which strategies were the most preferred.

Table 1. Reliability statistic of instrument.

\begin{tabular}{ccc}
\hline Cronbach's Alpha & Cronbach's Alpha Based on Standardized Items & No. of Items \\
\hline 0.782 & 0.769 & 12 \\
\hline
\end{tabular}


Table 2 presents the data of the 12 items under the seven strategies as in the table below. The study-preferences strategy $\left(7^{\text {th }}\right.$ strategies and $11^{\text {th }}$ item) and the open-ended item $\left(14^{\text {th }}\right.$ item $)$ will be discussed in the next tables. Thus, the overall items used in the survey were 12 items in total.

The survey finding illustrated that the best way to learn vocabulary is using the dictionary to find new words from reading. At least $10 \%$ of learners were strongly agreed that using English-Only dictionary to learn the English wordlists. This may indicate that learners have the awareness to learn English as to improve their comprehension in it without other language interruption. Furthermore, it was indicated that only $5 \%$ of the respondents less using dictionary to learn new vocabulary. It showed that the learners may prefer to use other strategies instead of referring to the dictionary alone. There is quite a significant result in dictionary strategies that $55 \%$ of learners were agree to use English-only dictionary to learn vocabulary since the others may prefer bilingual dictionary to comprehend the new English words.

The study indicated that most learners $(80 \%)$ were preferred to guess the meaning of new words that they are not familiar with before asks other person or look in the dictionary. Only $10 \%$ of the learners were strongly agreed that they use the same strategy. This may indicate that they are more likely to ask other person or look in the dictionary than guess the meaning by themselves, which is time consuming and mentally exhausting. Similarly, there are also 10\% of the learners who did not agree that they guess the meaning of words before asking other person or search them in the dictionary.

Majority of the respondents agreed that they preferred to write down the new words in their vocabulary notebook which is $85 \%$ under memory strategies. A total of $70 \%$ respondents also agreed that they try to remember the words by

Table 2. Vocabulary learning strategies responses.

\begin{tabular}{|c|c|c|c|c|c|c|}
\hline STRATEGIES & NO. & ITEMS & $\begin{array}{c}\text { SA } \\
1\end{array}$ & $\begin{array}{l}\text { A } \\
2\end{array}$ & $\begin{array}{l}\mathrm{D} \\
3\end{array}$ & $\begin{array}{c}\text { SD } \\
4\end{array}$ \\
\hline \multirow[t]{2}{*}{ Dictionary } & 1 & I use English-only dictionary & $2(10 \%)$ & $11(55 \%)$ & $7(35 \%)$ & 0 \\
\hline & 2. & $\begin{array}{l}\text { If I found a new word that I do not know in a reading passage, I search for } \\
\text { them in the dictionary. }\end{array}$ & $3(15 \%)$ & $16(80 \%)$ & $1(5 \%)$ & 0 \\
\hline Guessing & 3. & $\begin{array}{l}\text { I guess the meaning of words I am not familiar with before I ask someone } \\
\text { or look in the dictionary. }\end{array}$ & $2(10 \%)$ & $16(80 \%)$ & $2(10 \%)$ & 0 \\
\hline \multirow[t]{2}{*}{ Memory } & 4. & I write the new words I learned in a vocabulary notebook. & $1(5 \%)$ & $17(85 \%)$ & $2(10 \%)$ & 0 \\
\hline & 5. & I remember words by remembering the sentences that I saw in a passage. & $2(10 \%)$ & $14(70 \%)$ & $4(20 \%)$ & 0 \\
\hline \multirow[t]{2}{*}{$\begin{array}{l}\text { Autonomy } \\
\text { learning }\end{array}$} & 6. & $\begin{array}{l}\text { I read English books, newspaper, and magazines outside of class for my } \\
\text { own knowledge and pleasure. }\end{array}$ & $2(10 \%)$ & $15(75 \%)$ & $3(15 \%)$ & 0 \\
\hline & 7. & I listen to English songs and watch English movies outside of class time. & $4(20 \%)$ & $15(75 \%)$ & $1(5 \%)$ & 0 \\
\hline Note-taking & 8. & I write down a word or phrases that I think are useful. & $2(10 \%)$ & $14(70 \%)$ & $4(20 \%)$ & 0 \\
\hline \multirow[t]{2}{*}{ Social } & 9. & I ask my teachers, friends and parents for meaning of new words. & $9(45 \%)$ & $11(55 \%)$ & 0 & 0 \\
\hline & 10. & I try to speak English at school and outside of the school. & $7(35 \%)$ & $12(60 \%)$ & $1(5)$ & 0 \\
\hline
\end{tabular}


remembering the sentences that they encounter in a passage.

In autonomy learning, most of the respondents equally favored to read English materials such as book and magazines and enjoy English songs and movies after the class for their own knowledge and pleasure which is $75 \%$ each. Only $5 \%$ of the respondents interested to do so. This may occur as some of the learners in Primary 3 are not keen to encounter with English entertainment as it is not comprehensive to them.

It was also discovered that $70 \%$ of the learners preferred (agree) to write a word or phrases from an unknown reading materials that they think useful, and $20 \%$ of the responses stated that they do not like to do note-taking although the words may be useful to them.

One of the interesting strategies is through social strategies. From the study, it was indicated that most learners agreed that they like to try to speak English at school and outside the school. This is because they enjoyed practice speaking the language with their friends and parents. A total of $55 \%$ of learners also were agreed that they ask their teachers, parents, and friends if they want to know the meaning of new words. There were also 35\% of learners who were strongly agreed to try to speak English at school and after the school session. This shows a good sign that the Primary 3 pupils are ready to improve themselves in the language through social strategies through interaction with the people around them.

For the study Preferences, most learners like to study the vocabulary with other person which indicated $75 \%$ in total out of the others. This method of learning also known as the collaborative learning. In contrast, the other $25 \%$ of the learners prefer to study by refer to the dictionary and there are no respondents like to study English vocabulary alone (Table 3).

In Table 4, it is indicated that the most preferred strategies in learning the vocabulary was the dictionary strategies. When they answer the open-ended question, $40 \%$ learners more preferred using dictionary to find the accurate meaning and the sample of sentences of the words. The next most favorable strategy was autonomy-learning which indicated $25 \%$ of the respondents prefer to study and take control and responsible on their own learning, followed by $10 \%$ of the learners used the memory strategies when they like to write down the new words on their notebook and remember the unfamiliar words that they found in a reading passage. The less preferred strategies was social, the combination of

Table 3. Study preferences.

\begin{tabular}{lc}
\multicolumn{1}{c}{ ITEMS } & TOTAL \\
\hline When I study vocabulary, I work: & $0 \%$ \\
a) alone & $15(75 \%)$ \\
b) with other person & $5(25 \%)$ \\
c) by looking in the dictionary & 20 \\
Total & \\
\hline
\end{tabular}


Table 4. Open-ended responses.

\begin{tabular}{llcccc}
\hline & Frequency & Percent & $\begin{array}{c}\text { Valid } \\
\text { Percent }\end{array}$ & $\begin{array}{c}\text { Cumulative } \\
\text { Percent }\end{array}$ \\
\hline Valid & Dictionary Strategies & 8 & 40.0 & 40.0 & 40.0 \\
\cline { 2 - 3 } & 5 & 25.0 & 25.0 & 65.0 \\
Memory Strategies & 2 & 10.0 & 10.0 & 75.0 \\
Social Strategies & 1 & 5.0 & 5.0 & 80.0 \\
Dictionary and Social Strategies & 1 & 5.0 & 5.0 & 85.0 \\
Dictionary and Guessing Strategies & 1 & 5.0 & 5.0 & 90.0 \\
Dictionary, memory and social strategies & 2 & 10.0 & 10.0 & 100.0 \\
Total & 20 & 100.0 & 100.0 & \\
\hline
\end{tabular}

dictionary and social strategies, and dictionary with guessing strategies which had the same ratio with only 1 respondent each (5\%) in learning the vocabulary. Finally, the dictionary, memory and together with social strategies have the ratio of $10 \%$ of the respondents who preferred to combine all the three strategies in their vocabulary learning.

\subsection{The Relationship between Respondents' Language Competency and the Number of Vocabulary Learning Strategies Used}

The second research question aims to find the significant relationship between respondents' language competency and the number of vocabulary learning strategies employed. The survey data were gathered into SPSS software version 23 and the Pearson Correlation was employed to determine if there is the significant relationship results between the language competency and the Vocabulary Learning Strategies employed. The language competency results were obtained from the respondents' First Semester English Language Assessment for Primary 3 English CEFR (Common European Framework of References for Languages).

A Pearson Correlation analysis was conducted to examine the relationship between the pupils' language competency and the amount of vocabulary learning strategies used.

Table 5 indicates that there is no correlation between the competency and the strategies used that it is highly negative with the value of $r(-0.016)$ and the relationship is not significant with the $(p=0.947)$ calculated which is greater than $p$ $=0.05$. This finding signifies that pupils' language proficiency level has insufficient evidence to say it is influenced by their amount of vocabulary learning strategy usage. In fact, regardless of how many types of vocabulary learning strategies use, pupils' language competency can be influenced by any other factors, such as the amount of practices they have. This result is similar to the finding by Johannah et al. (2015) on the relationship between the overall English language learning strategies and proficiency of the pre-university students in UMS, Sabah. The correlation output between students' language learning strategy and their language proficiency was not significant. In the recent study, 
Table 5. Correlations between language competency and the amount of strategies used.

\begin{tabular}{cccc}
\hline & & Competency & STRATEGIESUSED \\
\hline Competency & Pearson Correlation & 1 & -0.016 \\
& Sig. (2-tailed) & & 0.947 \\
& $\mathrm{~N}$ & 20 & 20 \\
STRATEGIES USED & Pearson Correlation & -0.016 & 1 \\
& Sig. (2-tailed) & 0.947 & 20 \\
\hline
\end{tabular}

although the respondents only employ one or two strategies, their achievement can be either very poor or excellent depends on how much motivation, effort or the uses of strategies that they are currently applied.

\section{Discussion}

Overall, memory strategies were the most frequently used strategies (85\%) among the respondents that they like to write the new words they learned in the vocabulary notebook. This finding is align with Hadavi \& Hashemi (2014) when they discovered most EFL medical Sciences learners use memory strategies based on their survey items, followed by dictionary strategies and guessing strategies. It is also obvious that the pupils had a high frequency in using the learning strategies in efforts to acquire the English vocabulary. They were also applied other strategies such as autonomy-learning, note-taking, social strategies, and the study preferences either study alone or work with other peers.

In terms of memory strategies, the pupils prefer to write down the new words in their vocabulary notebook to memorize the words they just get to familiar with. For the dictionary strategies, the pupils were in need of using the dictionary in their early age in order to find and learn the words comprehensively. Gu \& Johnson (1996) have categorised this type of learners as "passive strategy users" and they consolidate the words they learned over time in their learning process.

Besides that, the pupils also employed guessing strategies extensively. Most of the pupils like to guess the word meaning before they ask someone or look in the dictionary. This strategies has its own benefit which in a certain extent, some vocabulary can be learned from real contexts. Based on a study by Shu et al., (1995), native speakers can discover "there is between a 1 in 10 and 1 in 20 chance of an unfamiliar item being learned to some degree" in the real situation or while reading. Although the pupils' native language is Bidayuh language, they can incidentally learn an average of few unknown words they met while reading English materials. Pupils whose family is the English speakers may learn more than average or more the unfamiliar words through listening to their parents' conversation, and when they speak to each other. Besides, pupils as early as Primary 3 are able to guess and memorize the words that are frequently used in 
their conversation and from other medium.

Researchers in the Second Language Acquisition (Fitzptrick et al., 2008; Lawson \& Hogben, 1996; Meara, 1995; Pulido, 2009; Schmitt, 2000) also claimed that at the beginning of lower proficiency level, learners who tend to use memorization "will have better results, whereas more advanced learners will benefit more from the context found in more cognitively-demanding tasks". For the autonomy learning, it is found that most learners were equally agreed to read English materials for own knowledge and pleasure, and listening to English songs and watch English movies to acquire the English vocabulary. This strategy is refer to "the ability to take charge of one's learning" (Holec, 1981) and could lead learners to be independent and proactive with less reliant to the teachers. Most pupils are gadget savvy and have the ability to subscribe to any English materials such as songs and movies by searching in the Internet and download them. This strategy, when used frequently will enable them to get familiarize with many English words. Farid \& Hassiba (2011) have revealed that the University of Constantine's first year students were benefited from the use of songs in acquiring vocabulary. Besides, the learners applied note-taking strategies and social strategies while learning, which they mostly strongly agreed with. Vocabulary Notetaking books were long introduced by few scholars such as McCarthy (1990) and Woolard (2000). Some benefits of note-taking are that it encourages the learners to develop self-learning and remembering words easily. Besides, it also promote effective learning since teachers sometimes have insufficient time to teach vocabulary, and note-taking will encourage learners to be more autonomous and independent.

\section{Implication of Study}

Due to the English Language development in the Malaysian Education, the Malaysian primary learners and teachers have to emphasis more on the use of vocabulary learning strategies to enhance the English vocabulary acquisition. Ediger (1999) have recommended that "developing students' vocabulary knowledge should be a major goal in each academic discipline". Educators have to understand that learners learn and develop their vocabulary knowledge continuously. On the other hand, educators have to cooperate and continuously provide supports and guidance to the pupils by sharing suitable vocabulary learning strategies and discuss some common problems regarding the vocabulary learning.

\section{Conclusion}

From the study, it is obviously that different learners have different style of learning and adopt different vocabulary learning strategies in their learning process. The findings revealed that the strategies that were used frequently are memory strategies, dictionary strategies and guessing strategies. Learners need to employ more useful learning strategies that are beneficial to master an extensive range of English vocabulary. Educators also can help to stimulate their in- 
terest to learn vocabulary using the ICT during their spare time at home. It is hoped that when they learn new words independently, they would never forget the newly-learned vocabulary. Therefore, the seven vocabulary learning strategies that have been studied are worth to be applied by the learners as early as Primary 3 and it is hoped that these strategies will give positive impacts towards their academic performance.

\section{Conflicts of Interest}

The authors declare no conflicts of interest regarding the publication of this paper.

\section{References}

Aitchison, J. (2003). Words in the Mind: An Introduction to the Mental Lexicon (3rd ed.). London: Blackwell.

Benson, P. (2001). Teaching and Researching: Autonomy in Language Learning. London: Longman.

Ediger, M. (1999). Reading and Vocabulary Development. Journal of Instructional Psychology, 26.

Fan, M. (2003). Frequency of Use, Perceived Usefulness, and Actual Usefulness of Second Language Vocabulary Strategies: A Study of Hong Kong Learners. Modern Language Journal, 87, 222-241. https://doi.org/10.1111/1540-4781.00187

Farid and Hassiba (2011). The Efficiency of Using Songs to Learn Vocabulary. The Case of 1st Year Students, University of Constantine. Research Proposal for the Partial Fulfillment of a Master Degree in Applied Language Studies, 2010-2011.

Fitzptrick, T., Al-Qarni, I., \& Meara, P. (2008). Intensive Vocabulary Learning: A Case study. Language Learning Journal, 36, 239-248. https://doi.org/10.1080/09571730802390759

Gu, Y., \& Johnson, R. K. (1996). Vocabulary Learning Strategies and Language Learning Outcomes. Language Learning, 46, 643-679. https://doi.org/10.1111/j.1467-1770.1996.tb01355.x

Hadavi, M., \& Hashemi, Z. (2014). Comparative Analysis of Vocabulary Learning Strategies in Learning English as a Foreign Language among Freshmen and Senior Medical Sciences Students across Different Fields of Study. Malaysia Journal of ELT Research, 10, 19-33.

Holec, H. (1981). Autonomy in Foreign Language Learning (p. 3). Oxford: Pergamon.

Johannah, J. K., Jumat, S., Suyansah, S., \& Wardatul, A. D. (2015). The Relationship between English Language Learning Strategies and Proficiency of Pre-University Students: A Study Case of UMS. AIP Conference Proceedings, 1605, 775.

Lawson, M., \& Hogben, D. (1996). The Vocabulary-Learning Strategies of Foreign-Language Students. Language Learning, 46, 101-135. https://doi.org/10.1111/j.1467-1770.1996.tb00642.x

Meara, P. (1995). The Importance of an Early Emphasis on L2 Vocabulary. JALT, 19, 8-11. http://www.jalt-publications.org/tlt/files/95/feb/meara.html

Nation, P. (2001). Learning Vocabulary in Another Language. Cambridge: Cambridge University Press. https://doi.org/10.1017/CBO9781139524759

Noor, N. M., \& Amir, Z. (2009). Exploring the Vocabulary Learning Strategies of EFL 
Learners. http://www.ukm.my/solls09/Proceeding/PDF/noorizah\%20and\%20zaini.pdf

O’Malley, J. M., \& Chamot, A. U. (1990). Learning Strategies in Second Language Acquisition. Cambridge: Cambridge University Press. https://doi.org/10.1017/CBO9781139524490

Oxford, R. L. (1990). Language Learning Strategies: What Every Teacher Should Know. Boston, MA: Newbury House.

Pritchard, R. (1990). The Effects of Cultural Schemata on Reading Processing Strategies. Reading Research Quarterly, 25, 273-295. https://doi.org/10.2307/747692

Pulido, D. (2009). How Involved Are American L2 Learners of Spanish in Lexical Input Processing Tasks during Reading? Studies in Second Language Acquisition, 31, 31-58. https://doi.org/10.1017/S0272263109090020

Schmitt, N. (2000). Vocabulary in Language Teaching. Cambridge: Cambridge University Press.

Schmitt, N., \& McCarthy, M. (1997). Vocabulary: Description, Acquisition and Pedagogy. Cambridge: Cambridge University Press.

Shu, H., Anderson, R. C., \& Zhang, Z. (1995). Incidental Learning of Word Meanings from Contexts. Journal of Reading Behaviour, 22, 71-97.

Waldvogel, D. A. (2013). The Relationship between Vocabulary Learning Strategies and Vocabulary Size among Adult Spanish Foreign Language Learners. Journal of Language Teaching and Research, 4, 209-219. https://doi.org/10.4304/jltr.4.2.209-219 